\title{
Amitriptyline induced Acute Dyskinesia
}

\author{
Mithun S. \\ Assistant Professor, Department of Psychiatry, Srinivas Institute of Medical Sciences \& \\ Research Centre, Mangalore, India \\ Email: mdmitsmj@gmail.com
}

Type of the Paper: Case Report.

Type of Review: Peer Reviewed.

Indexed In: OpenAIRE.

DOI: https://doi.org/10.5281/zenodo.3237435.

Google Scholar Citation: IJHSP

\section{How to Cite this Paper:}

Mithun, S. (2019). Amitriptyline induced Acute Dyskinesia. International Journal of Health Sciences and Pharmacy (IJHSP), 3(1), 40-42.

DOI: https://doi.org/10.5281/zenodo.3237435.

International Journal of Health Sciences and Pharmacy (IJHSP)

A Refereed International Journal of Srinivas University, India.

IFSIJ Journal Impact Factor for 2019-20 = 3.968

(C) With Author.

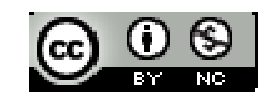

This work is licensed under a Creative Commons Attribution-Non Commercial 4.0 International License subject to proper citation to the publication source of the work.

Disclaimer: The scholarly papers as reviewed and published by the Srinivas Publications (S.P.), India are the views and opinions of their respective authors and are not the views or opinions of the SP. The SP disclaims of any harm or loss caused due to the published content to any party. 


\title{
Amitriptyline induced Acute Dyskinesia
}

\author{
Mithun S. \\ Assistant Professor, Department of Psychiatry, Srinivas Institute of Medical Sciences \& \\ Research Centre, Mangalore, India \\ Email: mdmitsmj@gmail.com
}

\begin{abstract}
Overall prevalence of tricyclic antidepressants (TCA's) causing extra-pyramidal features are low. Amongst them acute dyskinesia is not a commonly seen clinical presentation. Here, I describe a case of acute dyskinesia induced by amitriptyline. The challenges in the diagnosis and management are discussed.
\end{abstract}

Keywords: Amitriptyline, Dyskinesia, Clonazepam.

\section{BACKGROUND :}

Dyskinesia is one of the known extrapyramidal side effects (EPS) usually associated with use of antipsychotics [1]. Previously case reports of hyper-dyskinetic syndrome in patients receiving tricyclic antidepressants (TCA) have been described [1], [2]. The overall prevalence of TCA induced EPS side effects is low but their clinical implications are important [3]. Here I describe a case of a 38 year old female patient who presented with acute dyskinesia with use of amitriptyline.

\section{CASE REPORT :}

Mrs. X, a 38 year old married lady, homemaker, coming from a low socioeconomic status and was residing with her husband and two children. She came to casualty with complaints of reoccurring involuntary abnormal jerky movements of her upper limbs, difficulty in walking due to pelvic thrusting, upper lipprotruding movements from past 1 week. She was admitted by the physician in view of progressing symptoms with significant dysfunction. Baseline investigations of blood counts, sugars, haemoglobin, serum electrolytes, thyroid profile, liver and renal function tests were within normal limits. She had no other medical co-morbidities and nil significant past history. On clarification she reported to be taking Tab Amitryptyline $25 \mathrm{mg}$ at night from past 15 days, given to her over the counter (OTC) in view of insomnia.. Psychiatrist reference was given for evaluation of her insomnia and rationalisation of her medications.
On detailed clarification with the patient and her mother, 3 months history suggestive of depression precipitated by her financial stressors was evident. On physical examination the movements were typical of the clinical phenotype of dyskinesia. On Abnormal Involuntary Movements Scale (AIMS) scale she received a total score of 8,3 on severity index, 3 on incapacitation, 3 on patient's awareness of movements. She received a diagnosis of Adjustment DisorderBrief Depressive Reaction (F43.2) with Acute onset Dyskinesia (G24) as per ICD-10Classification of Mental and Behavioural Disorders [4]. Amitryptylline tablet was stopped and patient was started on clonazepam 0.25 1-0-1, mirtazapine 7.5mg 0-0-1. Over duration of next 5-6 days her dyskinetic movements had reduced significantly. Patient was discharged with mirtazapine $15 \mathrm{mg}$ and tapering doses of clonazepam.

\section{DISCUSSION :}

Acute Dyskinesia is an unusual presentation in comparision to tardive dyskinesia [5]. Acute onset dyskinesia is usually following a short term use (2-4 weeks) and tardive dyskinesia following 3 months use of antipsychotics [56]. The mechanism of acute dyskinesia is unclear but appears to be similar to tardive dyskinesia of increased dopamine receptor sensitivity [7]. As per Hill's criteria of causation, acute onset dyskinesia in this case was secondary to the use of Amitryptylline (TCA) [8]. The offending agent was stopped and patient started on clonazepam [9, 10] and mirtazapine [11]. But unlike previous reports, 
a notable difference here is that the dyskinesia subsided significantly without persistence after stoppage of the drug.

\section{CONCLUSION :}

Acute dyskinesia is an uncommon side effect seen generally and with use of TCA's. This adds to the case report literature of acute dyskinesia due to use of amityptylline. One needs to be aware of such side effects as amityrptylline has a variety of wide ranged uses in clinical settings of different specialities.

\section{REFERENCES :}

[1] Hiremath SB, Desai M. (2016). Amitriptyline induced cervical dystonia. J Sci Soc. Jan 1;43(1):38.

[2] Fann WE, Sullivan JL, Richman BW. (1976). Dyskinesias Associated with Tricyclic Antidepressants. Br J Psychiatry. May;128(5):490-3.

[3] Vandel P, Bonin B, Leveque E, Sechter D, Bizouard P. (1997). Tricyclic antidepressant-induced extrapyramidal side effects. EurNeuropsychopharmacol. Aug 1;7(3):207-12.

[4] bluebook.pdf [Internet]. [cited 2019 May 20]. Available from: https://www.who.int/classifications/icd/en/ bluebook.pdf

[5] Gupta P, Gupta R, Balhara YPS. (2018). Acute-onset orofacial dyskinesia with a single low dose of oral flupentixol: A case report. Indian $\mathrm{J}$ Psychol Med. Mar 1;40(2):189.
[6] Early-onset tardive dyskinesia in a neuroleptic-naive patient exposed to lowdose quetiapine - Walsh - 2011 Movement Disorders - Wiley Online Library [Internet]. [cited 2019 May 9]. Available from: https://onlinelibrary.wiley.com/doi/abs/10.1 002/mds. 23831

[7] Aquino CCH, Lang AE. (2014). Tardive dyskinesia syndromes: current concepts. Parkinsonism RelatDisord. Jan;20Suppl 1:S113-117.

[8] Hill AB. (2015). The environment and disease: association or causation? J R Soc Med. Jan;108(1):32-7.

[9] Kimiagar I, Dobronevsky E, Prokhorov T, Miniovitz A, Rabey JM. (2012). Rapid improvement of tardive dyskinesia with tetrabenazine, clonazepam and clozapine combined: a naturalistic long-term followup study. J Neurol. Apr 1;259(4):660-4.

[10] Haile K, Umer H. (2019). The use of clozapine and clonazepam coadministration in the treatment of a severe tardive dyskinesia: A case report. SAGE Open Med Case Rep. 7:2050313X19833254.

[11] Meco G, Fabrizio E, Di Rezze S, Alessandri A, Pratesi L. (2003). Mirtazapine in l-Dopa-Induced Dyskinesias. ClinNeuropharmacol. Aug; 26(4): 179. 